\title{
ARTICLE
}

\section{Upregulation of GADD45 $\alpha$ in light-damaged retinal pigment epithelial cells}

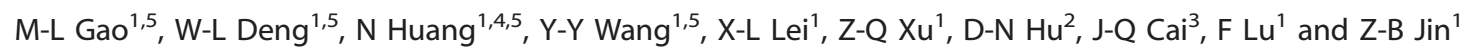

To better understand the molecular mechanisms responsible for light-induced damage in retinal pigmented epithelial (RPE) cells, we developed an automated device to recapitulate intense light exposure. When compared with human fibroblasts, ARPE-19 cells that had been exposed to blue-rich light-emitting diode-light of $10000 \mathrm{Lux}$ at $37^{\circ} \mathrm{C}$ for $9 \mathrm{~h}$ displayed dramatic cellular apoptosis. Collectively, gene expression profiling and qPCR demonstrated that growth arrest and DNA damage-45a (GADD45a) expression was markedly upregulated. Transient knockdown of GADD45a partially attenuated light-damage-induced apoptosis in ARPE-19 cells, whereas GADD45a overexpression dramatically increased it. These results demonstrate the critical function of GADD45a in light-induced RPE cellular apoptosis. Quantitative reverse transcription-PCR and western blotting revealed that the upregulation of GADD45a was under direct control of p53. Moreover, treatment with Ly294002, an inhibitor of AKT phosphorylation, further promoted GADD45a gene transcription in both non-light and light-damaged ARPE-19 cells. Treatment also exacerbated RPE cellular apoptosis after light exposure, confirming that inhibition of Akt phosphorylation increases GADD45a expression. Collectively, our findings reveal that light irrigation induces human RPE cellular apoptosis through upregulation of GADD45a expression mediated through both the p53 and phosphatidylinositol 3-kinase-AKT signaling pathways. These results provide new insights into human retinal diseases elicited by light damage and open a new avenue for disease prevention and treatment.

Cell Death Discovery (2016) 2, 16013; doi:10.1038/cddiscovery.2016.13; published online 29 February 2016

It has long been recognized that excessive light exposure produces photochemical lesions in the retina, ultimately leading to the damage of retinal pigmented epithelial (RPE) cells and the neural retina. ${ }^{1,2}$ Results from previous studies suggest that light-induced RPE damage may be one of the most important factors associated with age-related macular degeneration, solar retinopathy, and other retinal degenerative lesions. ${ }^{3-6}$ To this end, RPE cells are particularly susceptible to wavelengths within the blue region of the spectrum., ${ }^{7,8}$ Despite this, many aspects of lightinduced damage to RPE cells remain unclear, with the biological mechanisms behind such damage virtually unknown.

As shown in a variety of past studies, the apoptotic pathway is the main avenue for light-induced cell death, ${ }^{9,10}$ which then led to a pathway including execution and modulation by Caspase- 3 and $\mathrm{BCl}-2$, respectively. ${ }^{11-13}$ Furthermore, previous work has demonstrated that not only is a caspase-dependent apoptotic pathway involved in RPE cellular apoptosis, but also variety of cellular compartments, including mitochondria, lysosomes, and proteasomes. ${ }^{14-16}$

Recently, light pollution has become increasingly more common with the advent of new technologies and devices in domestic lighting, which has drawn the attention of researchers in the retinal degeneration field. ${ }^{17}$ Among these new devices, the most widely used are light-emitting diodes (LEDs), which present the greatest concern. On the technical level, LEDs have many advantages, including long life and low energy consumption. However, the LED spectrum range includes and delivers intense blue light components to the retina-more intense than normal daylight or more conventional domestic lighting sources. ${ }^{18}$ Although previous studies have focused on how blue light damages RPE cells, the effect of LEDs on the retina still requires much work, with particular focus needed for the molecular mechanisms behind such damage.

In this study, we have developed an instrument with controllable light intensity and temperature to imitate lightinduced apoptosis on RPE cells. Using this in vitro surrogate, we found serious RPE cellular apoptosis resulting from extensive exposure to blue-intensive LED light. We then found increased expression of growth arrest and DNA damage-45a (GADD45a), a marker of DNA damage, which plays a critical role in the progression of light-induced RPE cellular apoptosis. In addition, the upregulation of GADD45a may be directly regulated by the p53 signaling pathway and indirectly by the phosphatidylinositol 3-kinase (PI3K)-AKT signaling pathway. Taken together, our research offers a novel target for light-induced visual impairment.

\section{RESULTS}

Lighting system

Our SmartLight2.0 instrument with controllable light intensity and temperature was developed to allow for direct and intense blue-rich LED light exposure to cultured cells (Figure 1a). As shown

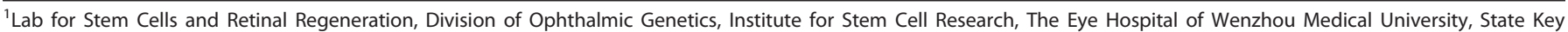

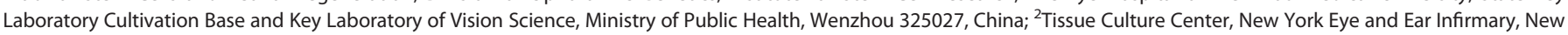
York Medical College, Valhalla, 10595 New York, USA and ${ }^{3}$ China National Institute of Standardization, Beijing 100191, China.

Correspondence: Z-B Jin (jinzb@mail.eye.ac.cn) or F Lu (lufan@mail.eye.ac.cn)

${ }^{4}$ Current address: Heze Municipal Hospital, Shandong 274031, China.

${ }^{5}$ These authors contributed equally to this work.

Received 3 December 2015; revised 21 December 2015; accepted 24 December 2015; Edited by A Rufini
} 
a

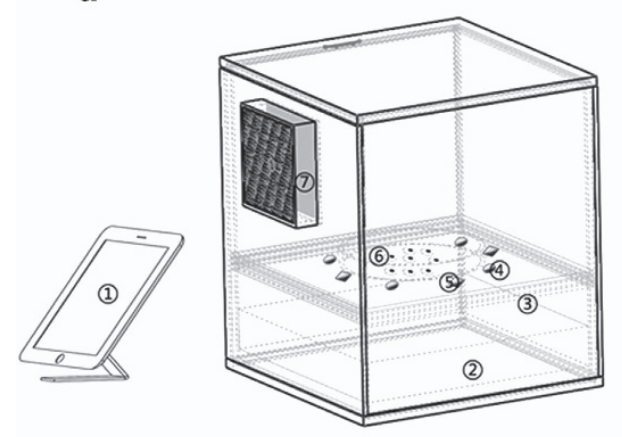

c

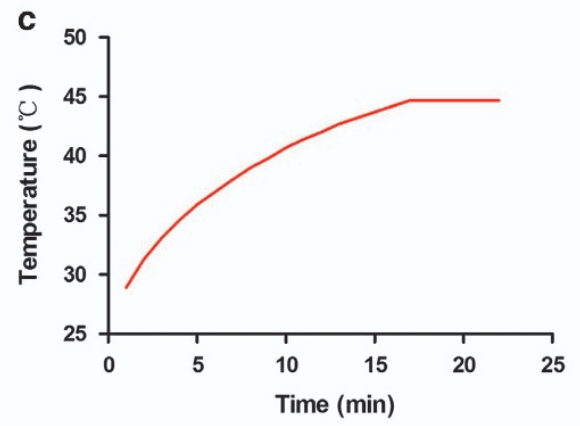

e

e

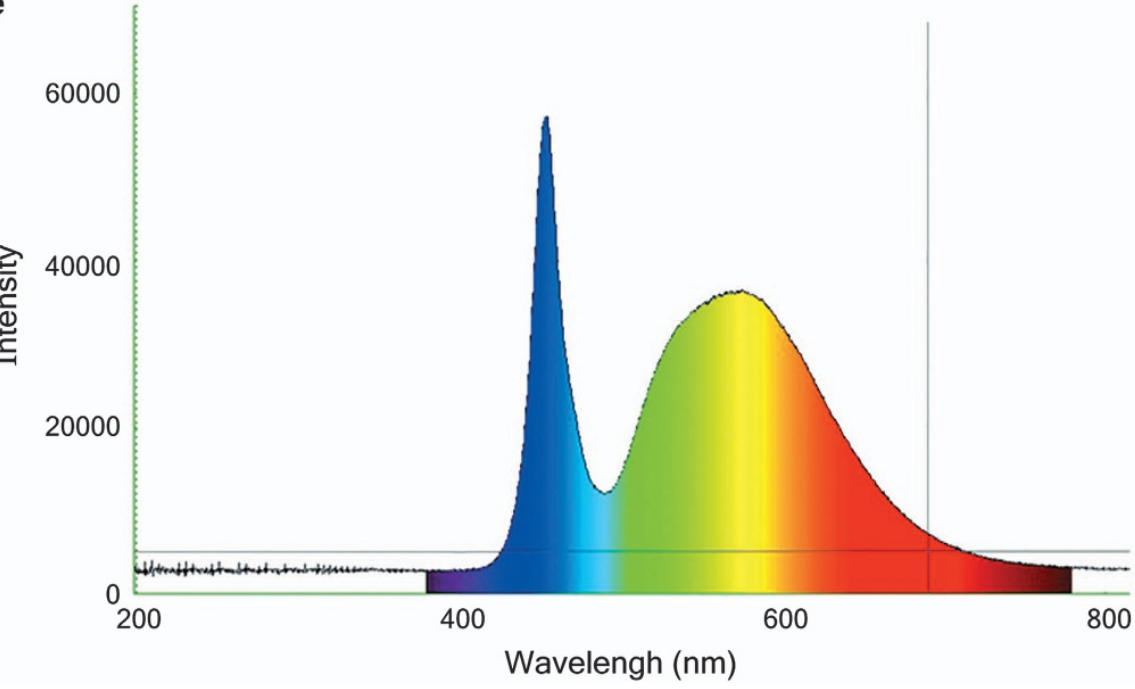

b
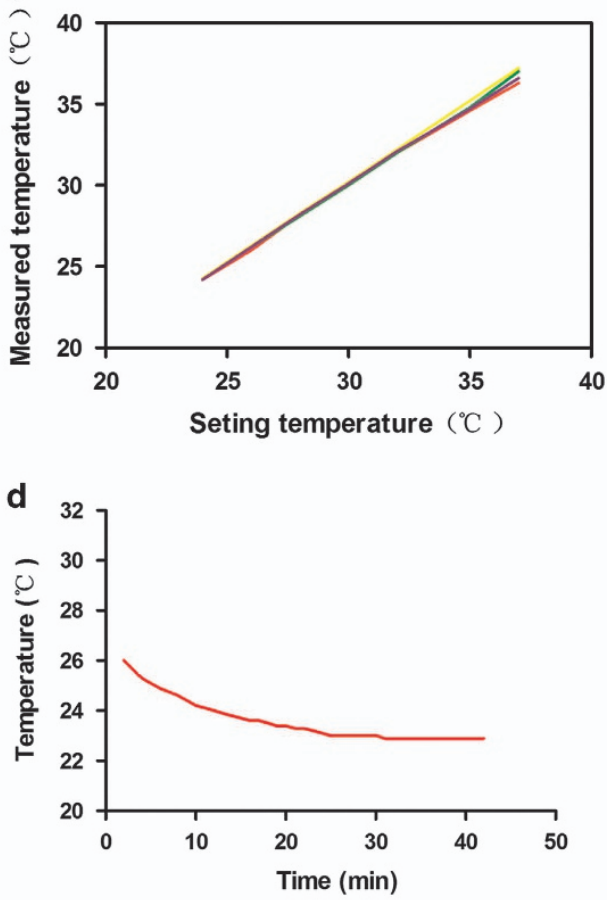

Wavelengh $(\mathrm{nm})$

Figure 1. Instrumental architecture of the homothermal lighting system. (a) Components of the instrument include: (1) display control screen, (2) LED light source, (3) optical filter, (4) temperature sensors, (5) light-intensity sensors, (6) dish-drop zone, and (7) semiconductor refrigeration tablets. (b) The four lines represent the four points on which temperatures were monitored by four sensors, showing high consistency in all four. (c) $15 \mathrm{~min}$ is required to completely warm the dish space from 20 to $45^{\circ} \mathrm{C}$. (d) 30 min is required to completely and stably lower the temperature from 27.2 to $20^{\circ} \mathrm{C}$. (e) The action spectrum of the LED light, as determined spectrometrically.

in Table 1, the instrumental parameters, including light intensity, temperature adjustment, temperature error, and light error were validated in triplicate. The temperature of four different areas showed no spatial variation (Figure 1b), with any variations returning quickly to the set value (Figure $1 \mathrm{c}$ and d). In addition, light intensity could be set to any value at or below 12000 Lux. The LED light action spectrum is shown in Figure 1e, with peaks occurring predominantly at the wavelength of blue light $(470 \mathrm{~nm})$. Taken together, these results demonstrate that SmartLight2.0 has stable, controllable parameters, making it a feasible instrument to model light-induced damage in vitro.
Light-induced apoptosis in human RPE cells

To determine the effect of intense LED light on RPE cells in our system, we used ARPE-19 cells along with differential light intensity exposure. We found that light intensity within a range of $10000-$ 12000 Lux resulted in cell death (Figure 2a). Given this finding, we then determined cell viability in a time-dependent manners using a light intensity of 10000 Lux. The viability of ARPE-19 cells treated with $4.5 \mathrm{~h}$ of 10000 Lux light decreased to $88.0 \%$ when compared with non-light controls. Furthermore, the proportion of cells surviving declined as a function of increased exposure time (Figure 2b). Human fibroblasts were unaffected (Figure 2c). 
To determine whether the decline in cellular viability was the result of cellular apoptosis, we performed both mitochondrial membrane potential and Annexin- $\mathrm{V} /$ propidium iodide (PI) double staining assays. The mitochondrial potential assay revealed that ARPE-19 cells underwent apoptosis after light exposure (Figure 2d). Moreover, that the percentage of apoptotic cells in the light-damaged condition was dramatically higher than in nonlight controls (Figure 2e). In addition, Annexin-V/PI staining showed that late-stage apoptosis/necrosis was induced after $9 \mathrm{~h}$ of exposure to 10000 Lux illumination (Figure 2f). These data collectively suggest that blue-rich LED light triggers apoptosis in ARPE-19 cells.

Table 1. Parameters of SmartLight2.0 lighting system

\begin{tabular}{lc}
\hline Parameter & Range \\
\hline Light intensity range & $0-12000$ Lux \\
Temperature adjustment range & $20-40{ }^{\circ} \mathrm{C}$ \\
Temperature error range ${ }^{\mathrm{a}}$ & $<37 \pm 0.4^{\circ} \mathrm{C}$ \\
Light error range $^{\mathrm{a}}$ & $<10000 \pm 420 \mathrm{Lux}$ \\
\hline
\end{tabular}

${ }^{\mathrm{a}}$ The data represent mean value \pm S.E. of three detection.
Light activates GADD45a signaling

To identify differentially regulated genes, we employed microarrays targeting human genes. Analyses of gene expression data showed that 2467 genes were differentially regulated after light illumination. When compared with non-light-exposed cells, 1656 of these initial candidate genes were upregulated and 811 genes were downregulated in light-exposed ARPE-19 cells (Figure $3 a$ and Supplementary Table 1). We then used gene annotation analysis of gene ontology (GO) terms to identify pathways and processes of these regulated genes that had significant enrichment (Figure 3b). We found that, in lightdamaged ARPE-19 cells, GO terms were highly enriched in pathways associated with apoptosis, cell cycle arrest, and DNA repair (Figure 3b). Among these, we identified the p53 hypoxia pathway, which controls the cell cycle when there is DNA damage, ultimately leading to cell apoptosis if the damage cannot be repaired. In the p53 signaling pathway, one of the gene with maximal change was GADD45a, with an eightfold high change than controls (Figure 3c). GADD45a has been identified as a regulator of apoptosis and cell cycle arrest. ${ }^{19,20}$ This protein participates in the p53 hypoxia pathway as well as G2/M checkpoint to regulate the cell cycle and cell growth in response a

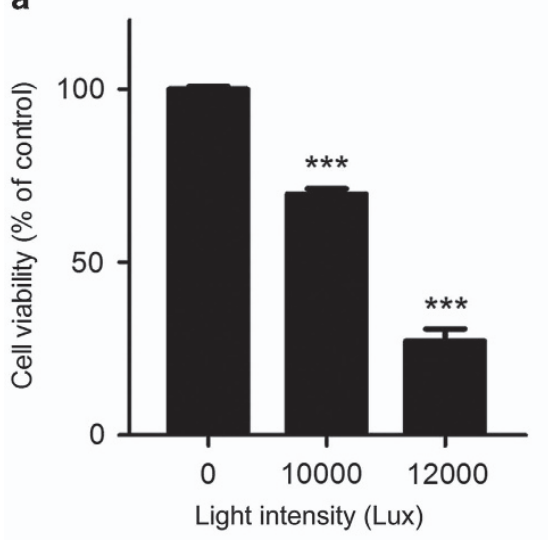

d

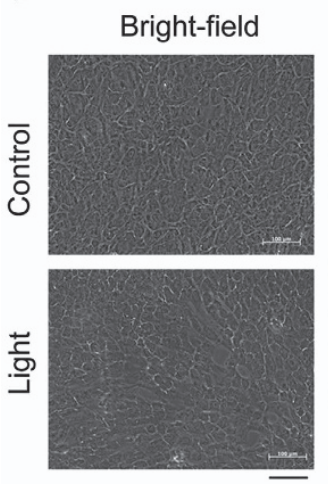

b

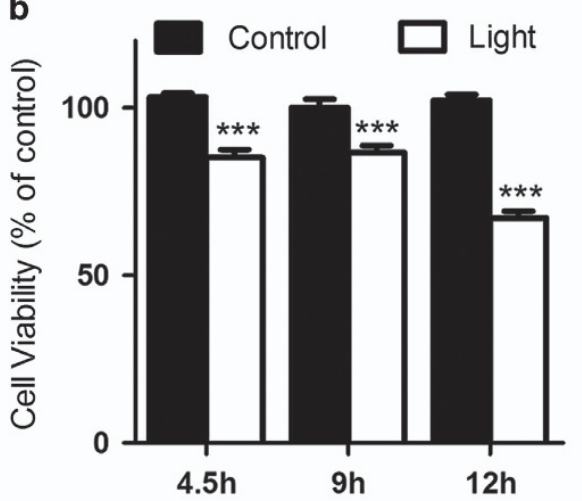

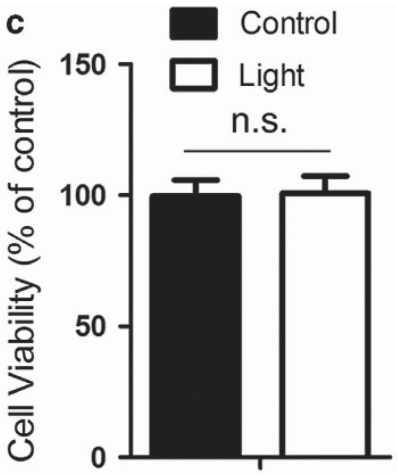




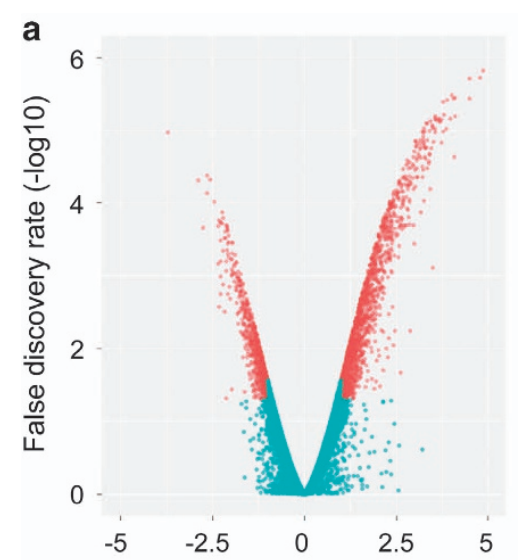

Fold change of expression ( $\log 2)$ Light-damaged vs non-light control cells

\section{b}

$$
\text { P-value }(-\log 10)
$$

Ajust P-value (-log10)

HIF-1-alpha transcription factor network Cyclin E associated events during G1/S transition Hypoxia and p53 in the Cardiovascular system C-MYC pathway

Genes involved in G1 Phase

$\mathrm{PI} 3 \mathrm{~K}$ events in ERBB4 signaling

Downstream Signaling Events Of B Cell Receptor Destabilization of mRNA by AUF1 (hnRNP D0) Negative regulation of the PI3K/AKT network Regulation of mRNA Stability by Proteins that Bind AU-rich Elements

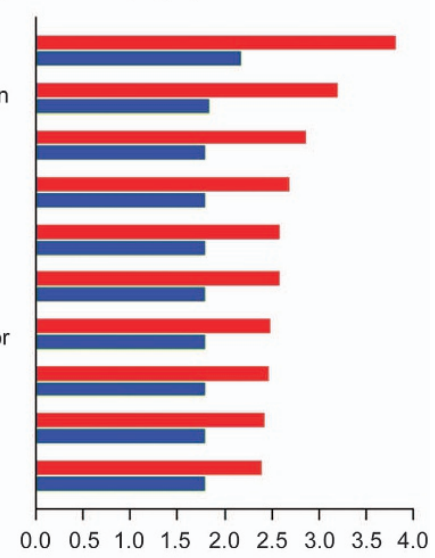

C

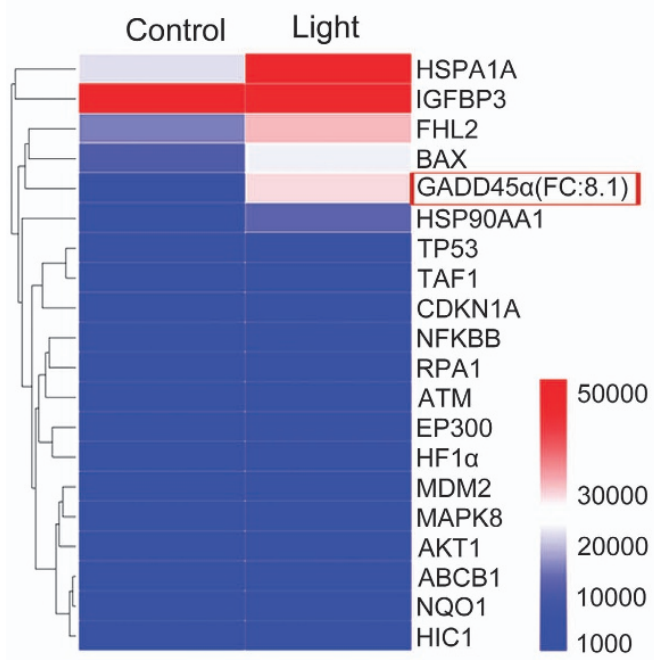

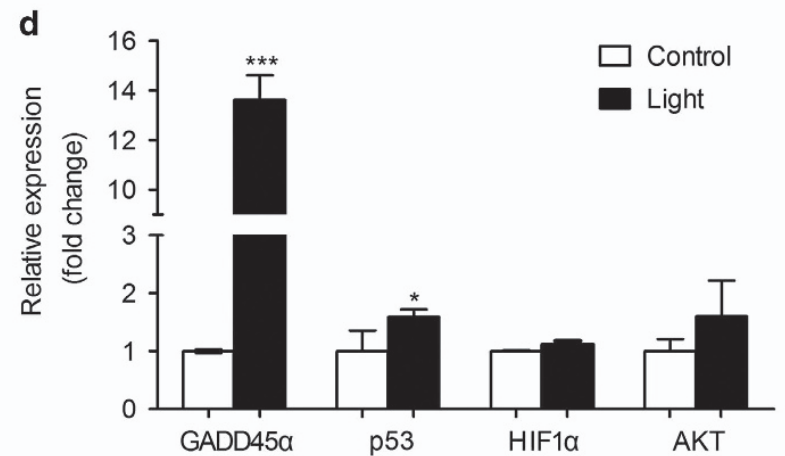

e

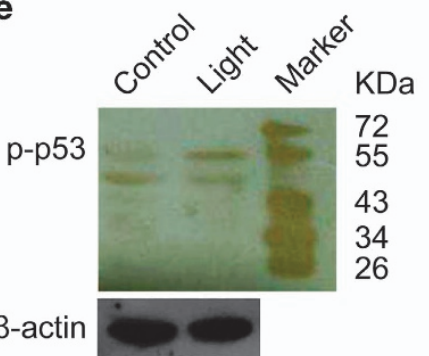

Figure 3. Gene expression profiling. (a) Schematic representations of the gene expression profiling in human OneArray experiments carried out in ARPE-19 cells. (b) Gene ontology (GO) analysis demonstrated differentially expressed pathways between non-light-damaged and lightdamaged cells. (c) Gene expression signature of light-damaged ARPE-19 cells in the p53 hypoxia pathway. (d) Quantitative RT-PCR was performed to confirm the results from our GO analysis. mRNA levels were standardized to the control gene $\beta$-actin. Results are presented as mean value \pm S.E.M. $\left(n=3,{ }^{*} P<0.05,{ }^{* * *} P<0.001\right)$. (e) Western blotting showed upregulation of $p$-p53 in light-damaged cells. The $\beta$-actin loading control is from the same experiment as shown in Figure $5 a$ and is reproduced in this figure for ease of reference.

to various environmental stresses. ${ }^{19}$ We used quantitative reverse transcription-PCR (qRT-PCR) to confirm that changes to GADD45a and found it to be markedly upregulated in light-damaged ARPE-19 cells (Figure 3d). Notably, we also found that the expression of transcription factor p53 was significantly higher in light-damaged ARPE-19 cells than in non-light controls (Figure $3 \mathrm{~d}$ ). In addition, the expression of activated p53 (phosphorylated p53, p-p53) was upregulated after light exposure (Figure $3 e$ and Supplementary Figures 1 and 2).

GADD45a upregulation is a key process in light-damaged ARPE-19 cells

The next question we asked was whether GADD45a upregulation causally resulted in ARPE-19 apoptosis. To address this, we investigated the role of GADD45a in ARPE-19 cells. First, overexpression of GADD45a led to a significant dose-dependent decline of cell viability when compared with vehicle control (Figure 4a). Furthermore, forced expression of GADD45a markedly exacerbated cell death in light-exposed ARPE-19 cells (Figure 4b). To further elucidate the biological effect of GADD45a in lightinduced apoptosis, we silenced GADD45a in ARPE-19 cells using lentiviral delivery of short hairpin RNAs (shRNAs; Figure 4c). Knockdown of GADD45a significantly reversed the previously observed cell viability reduction in light-damaged ARPE-19 cells (Figure 4d). Since the decrease in cell viability was primarily caused by apoptosis, these data strongly suggest that GADD45a is an important regulator of light-induced apoptosis of RPE cells in vitro.

Dephosphorylation of AKT in light-damaged RPE cells

As shown in the GO term analysis presented in Figure 3b, the PI3KAKT network was downregulated in light-damaged ARPE-19 cells. 

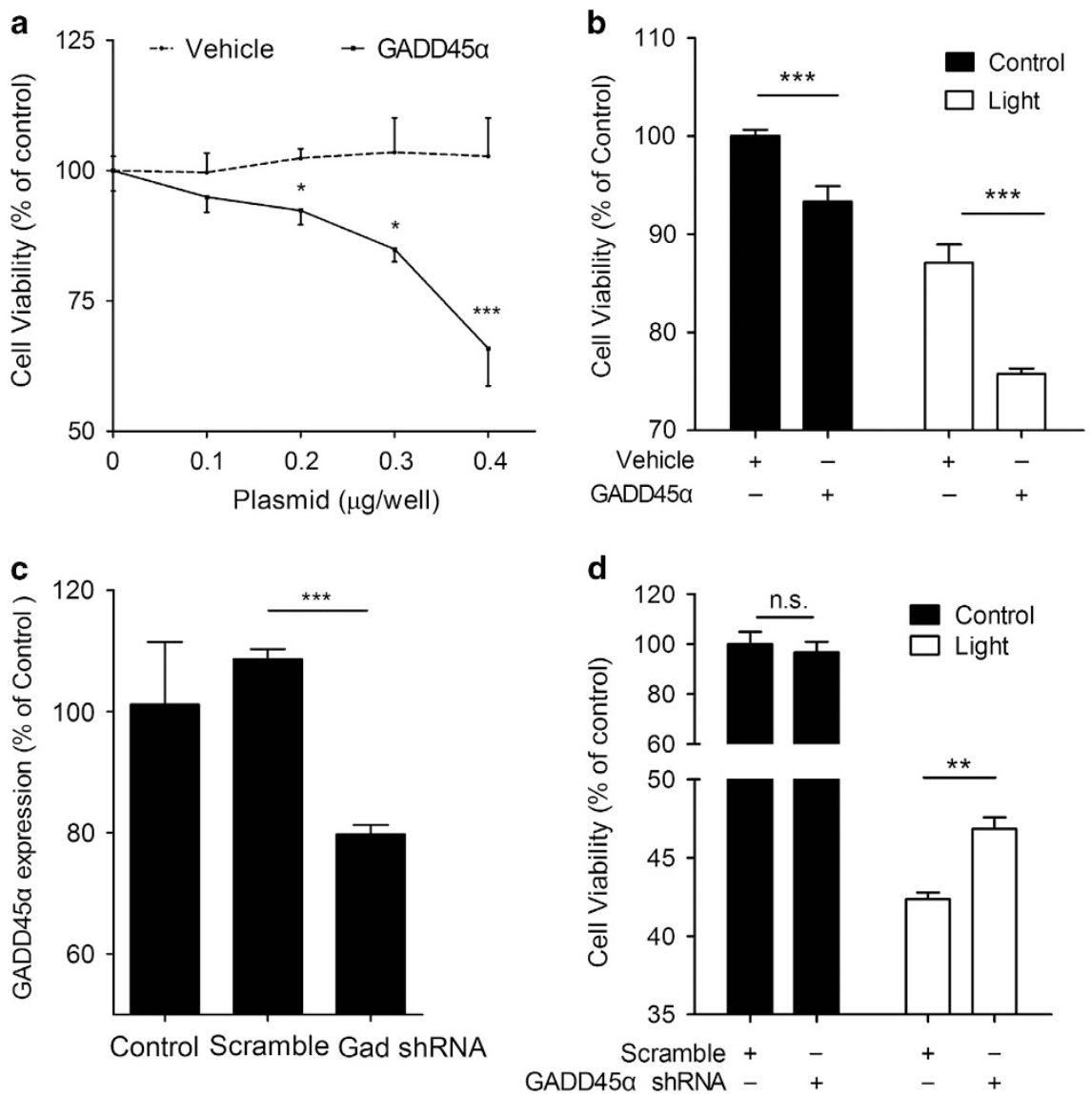

Figure 4. GADD45a stimulates apoptosis in ARPE-19 cells. (a) Overexpression of GADD45a in ARPE-19 cells resulted in a dose-dependent decrease in cell viability. Each point represents the mean value \pm S.E.M. $\left(n=4,{ }^{*} P<0.05, * * * P<0.001\right)$. (b) Overexpression of GADD45a significantly decreased cell viability, either with or without light damage. Each point represents the mean value \pm S.E.M. ( $n=4,{ }^{* * *} P<0.001$ ). (c) Knockdown of GADD45a in ARPE-19 cells using lentiviral delivery of shRNA. Results are given as mean value \pm S.E.M. ( $n=3, * * * P<0.001$ ). (d) Silencing GADD45a significantly reversed apoptosis in light-damaged RPE cells. Each value represents the mean value \pm S.E.M. $(n=4, * * P<0.01)$.

Phosphorylated AKT (p-AKT) levels (Figure 5a and Supplementary Figures 3 and 4) and cell viability were also remarkably decreased in light-damaged ARPE-19 cells (Figure 2b). We next wanted to address whether inhibition of AKT phosphorylation aggravated RPE cellular apoptosis. To do so, we used the AKT phosphorylation inhibitor Ly294002. ARPE-19 cells pretreated with $20 \mu \mathrm{M}$ Ly294002 followed by exposure to light displayed higher levels of AKT dephosphorylation (Figure 5a) and exacerbated apoptosis (Figure 5b). Surprisingly, higher expression of GADD45a was also observed after Ly294002 treatment, either with or without light exposure (Figure $5 \mathrm{c}$ ). Collectively, these findings support the idea that AKT activation plays a key role in light-induced apoptosis in ARPE-19 cells. Furthermore, that the PI3K-AKT pathway might play an important role in the upregulation of GADD45a.

\section{DISCUSSION}

In the present study, we have shown that in vitro exposure of human RPE cells to 10000 Lux of blue-rich LED light led to apoptosis via upregulation of GADD45a. Both GADD45a overexpression and gene silencing results suggest that GADD45a serves as a crucial molecule in light-induced RPE apoptosis. Further investigation indicated that GADD45a expression is regulated directly by p53 signaling and is likely indirectly affected by the PI3K-AKT pathway.
Blue light damages RPE

Thus far, great strides have been made to develop in vitro systems that mimic light damage in retinal cells. ${ }^{21,22}$ Early attempts by Noell $^{23}$ using fluorescent lamps from General Electric Circline demonstrated uneven and unstable illumination of RPE cells. To overcome these challenges, we developed an experimental instrument for this study that we validated in terms of its homothermal and adjustable illumination. These properties enabled us to allow for a stable system for use in subsequent experiments (Figures 1a-d).

Optical radiation includes UV, visible light, and infrared radiation. Most ultraviolet radiation is absorbed by the cornea and blocked by the lens. ${ }^{24-26}$ However, the maximally transmitted radiation through transparent media is visible light. Mounting evidence suggests that excessive light exposure might be a significant risk factor in age-related diseases, such as age-related macular degeneration, ${ }^{27,28}$ itself the global leading cause of blindness. Previous studies have shown that the blue region of the spectrum is the most damaging to RPE cells. ${ }^{12,14,29}$ Thus, we investigated how blue-rich LED light, which has a shorter wavelength peak at $470 \mathrm{~nm}$ (Figure 1e), damages RPE cells.

\section{Light damage leads to GADD45a upregulation}

In the present study, we found that exposure of RPE cells to intense blue-rich LED light led to an upregulation of GADD45a. GADD45a is a member of the growth arrest and DNA damage 


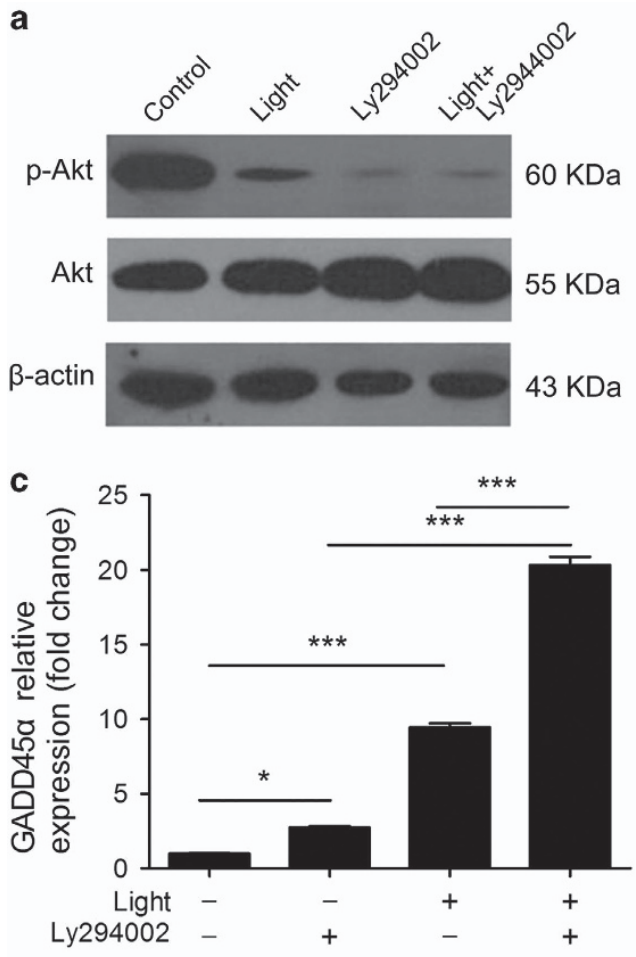

b
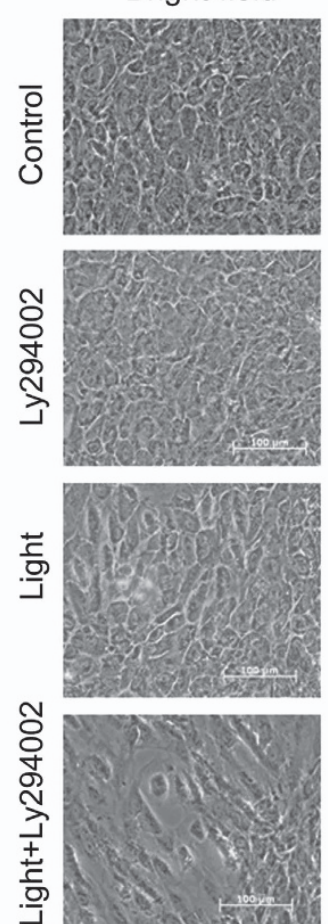

Bright-field
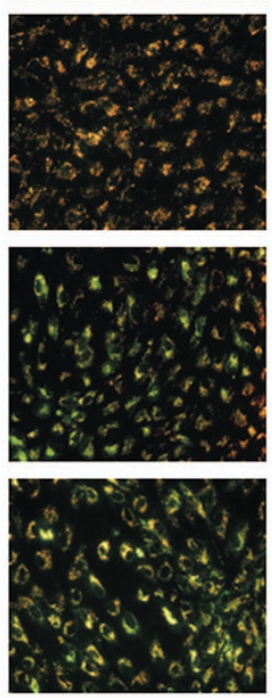

Figure 5. AKT dephosphorylation exacerbates apoptosis and enhances GADD45a expression. (a) Western blotting demonstrated increased dephosphorylation of AKT after light exposure and Ly294002 treatment of RPE cells after $4.5 \mathrm{~h}$ of exposure to 10000 Lux white light. The $\beta$-actin loading control is from the same experiment as shown in Figure $3 e$ and is reproduced in this figure for ease of reference. (b) ARPE-19 cells treated with Ly294002 or exposed to 10000 Lux white light for $4.5 \mathrm{~h}$ showed significant changes in mitochondrial membrane potential, as measured by JC-1. Bar $=100 \mu \mathrm{m}$. (c) RT-PCR showed that GADD45a expression was significantly upregulated after $4.5 \mathrm{~h}$ of light exposure and/or Ly294002 treatment. Results are given as mean value \pm S.E.M. $\left(n=3,{ }^{* * *} P<0.001,{ }^{*} P<0.05\right)$.

(GADD)-inducible proteins whose transcript levels are increased following cellular stress and DNA damage. ${ }^{20}$ Previous work has reported that mitochondrial DNA lesions occurred in lightexposed RPE cells through the actions of reactive oxygen species. ${ }^{14}$ GADD45a has been found to directly inhibit the activity of Cdc2/Cyclin B1 complex, resulting in G2 delay after UV radiation. ${ }^{30}$ We suspect that in light-damaged RPE cells, GADD45a was produced to arrest cells in G2/M in order for (i) DNA repair to occur or (ii) to overcome light-induced stresses. Notably, silencing GADD45a significantly reversed light-induced apoptosis, strongly suggesting its role as a therapeutic or preventative target and warranting further investigation in vivo. Collectively, our findings confirm the crucial role GADD45a plays in light-induced RPE apoptosis. To the best of our knowledge, this is the first report showing that GADD45a is upregulated in light-damaged RPE cells.

\section{Regulation of GADD45a in light-damaged RPE}

It is generally accepted that the transcription factor $\mathrm{p} 53$ regulates GADD45a expression in many stressed cell types. ${ }^{31-33}$ In the present study, qRT-PCR and western blotting demonstrated that both the transcription of p53 and its activated form (p-p53) were increased in light-damaged ARPE-19 cells. These data indicate that p53 directly regulates GADD45a expression.

As previous studies have shown, the PI3K-AKT pathway contributes to improved cell survival in response to light exposure. ${ }^{34,35}$ Light-induced AKT inhibition can be stimulated by PI3K-dependent and -independent mechanisms. ${ }^{36,37}$ Ly294002, a PI3K inhibitor, has been commonly used to block AKT activation. $^{38,39}$ Our study showed that Ly294002 markedly inhibited AKT activation and exacerbated light-induced apoptosis in RPE cells (Figure 5b). These findings strongly suggest that light exposure triggers the AKT survival pathway in RPE cells via a PI3K-dependent pathway. Notably, we discovered that the inhibition of AKT phosphorylation promotes GADD45a transcription (Figure $5 \mathrm{c}$ ), supporting the idea that PI3K-AKT signaling might participate in the regulation of GADD45a expression.

Given this, it should be noted that we cannot conclusively elucidate the relationship between GADD45 $a$ and AKT phosphorylation. However, this is not the first report showing that GADD45a expression might be regulated through AKT levels. For instance, in Hepatitis C-infected cells, p53 expression was downregulated by increased AKT phosphorylation. This ultimately led to a decline in GADD45a expression. ${ }^{40}$ Thus, it is plausible that the expression of GADD45a might be mediated by p53 via PI3K-AKT signaling.

\section{CONCLUSION}

In summary, we have shown that blue-rich light exposure of RPE cells induces significant cell apoptosis through GADD45a upregulation, itself mediated via p53 and AKT dephosphorylation. Regulation of GADD45a significantly alters light-induced apoptosis and may be a potential target for therapeutic purposes, opening up a novel avenue for light-damage-related retinal disease prevention and treatment.

\section{MATERIALS AND METHODS}

Development of a quantitative instrument, SmartLight2.0 We built an experimental instrument, SmartLight2.0, to model light damage on retinal cells without the confounding effect of thermal damage. SmartLight2.0 is a balanced, adjustable LED system that is homothermal, which is achieved through utilization of an automatic cooling fan for thermostatic protection. SmartLight 2.0 is composed of the 
Table 2. Primer set for qRT-PCR

\begin{tabular}{|c|c|c|c|}
\hline Gene & Primer sequences $\left(5^{\prime} \rightarrow 3^{\prime}\right)$ & Product size (bp) & Annealing temperatures $\left({ }^{\circ} \mathrm{C}\right)$ \\
\hline GADD45a & CACAACACCACGTTATCGGG & & 60.5 \\
\hline \multirow[t]{2}{*}{ AKT1 } & AGCGACGTGGCTATTGTGAAG & 96 & 62.7 \\
\hline & GCCATCATTCTTGAGGAGGAAGT & & 61.9 \\
\hline HIF1a & GGCGCGAACGACAAGAAAAAG & 154 & 59.8 \\
\hline$\beta$-Actin & AGCACTGTGTTGGCGTACAG & & 60.5 \\
\hline
\end{tabular}

following parts: a display control screen, a camera obscura, an LED light, a semiconductor chilling unit, a light-to-digital converter, a temperature sensor, light-intensity sensors, and a feedback cooling fan system. The cell culture dish used in each study is placed in the center of the top of the platform. Differences in temperature were measured between the measured data and a previously applied setting. Furthermore, temperature controlling system was tested. To assess the action spectrum of the LED light, a spectrometer (Maya2000 Pro, Ocean Optics, Dunedin, FL, USA) was used.

\section{Cell culture}

Human RPE cells (ARPE-19, ATCC No: CRL-2302) obtained from ATCC in Chicago, IL, USA, are an immortalized cell line obtained from a 19-year-old donor, which were seeded in 12-well plates and T25 flasks. Cells were cultured in Dulbecco's modified Eagle's medium (DMEM, Gibco, Grand Island, NY, USA) supplemented with $10 \%$ fetal bovine serum (Gibco) and $100 \mathrm{U} / \mathrm{ml}$ Penicillin-Streptomycin (Gibco $)^{41}$ before being incubated in a humidified $5 \% \mathrm{CO}_{2}$ chamber at $37^{\circ} \mathrm{C}$. After reaching $90 \%$ confluence, medium was replaced with DMEM with $1 \mathrm{~g} / \mathrm{l}$ glucose and pyruvate, $1 \%$ FBS and $100 \mathrm{U} / \mathrm{ml}$ Penicillin-Streptomycin, and then cultured for 2 months before light exposure. ${ }^{42}$

As a control, primary human fibroblasts were obtained from normal skin following nevus resection (with informed consent and approval from the Ethics Committee of our institute) and then purified according to the standard procedures. ${ }^{43}$ In brief, dermal tissue was cut into $3 \mathrm{~mm}^{2}$ pieces and dermal explants were plated in $25 \mathrm{~cm}^{2}$ flasks. They were subsequently incubated with DMEM medium containing $20 \%$ FBS and $100 \mathrm{U} / \mathrm{ml}$ Penicillin-Streptomycin at $37^{\circ} \mathrm{C}$ and in a humidified $5 \% \mathrm{CO}_{2}$ chamber to allow fibroblast proliferation. After one week, the dermal clumps were removed and the fibroblasts were incubated with 10\% FBS/DMEM medium until $90 \%$ confluence. Cells were then split and seeded into $10 \mathrm{~cm}$ dishes $\left(2.5 \times 10^{6}\right.$ cells/dish). ${ }^{44,45}$

\section{Light exposure}

Before light exposure, cells were washed three times with phosphatebuffered saline and the medium was replaced with modified DMEM (without folate photosensitive material, phenol red, riboflavin, L-tryptophan, or L-tytosine) (Gibco). ARPE-19 and primary human fibroblasts were then subjected to blue-rich LED light using our SmartLight2.0 to examine the resulting light damage.

\section{Cell viability assay}

The viability of cells cultured in 96-well plates was then measured using the WST-1 cell proliferation and cytotoxicity assay kit (Roche, Mannheim, Germany) and according to the manufacturer's instructions. Absorbance at the experimental wavelength of $440 \mathrm{~nm}$ and the reference wavelength of $\sim 630 \mathrm{~nm}$ were monitored using Spectra Max M5 (Molecular Devices, Sunnyvale, CA, USA).

\section{Mitochondrial membrane potential assay $(\Delta \psi m)$}

$\Delta \psi m$ was analyzed using a JC-1 assay kit (Beyotime, Nantong, Jiangsu, China) and according to the manufacturer's instructions. Briefly, cells were cultured and treated on coverslips in 24-well plates, followed by incubation with an equal volume of $\mathrm{JC}-1$ staining solution at $37^{\circ} \mathrm{C}$ for $20 \mathrm{~min}$. After two rinses with phosphate-buffered saline, the $\Delta \psi m$ were monitored by determining the relative amount of dual emissions from mitochondrial
JC-1 monomers (green fluorescence) or aggregates (red fluorescence) using a fluorescent microscope (Zeiss, Gottingen, Germany).

\section{Annexin-V/PI double staining}

ARPE-19 cellular apoptosis and necrosis were analyzed using an AnnexinV-FLOUS staining kit (Roche). In brief, coverslips containing ARPE-19 cells were incubated in Annexin-V-FLOUS and PI labeling solution for $15 \mathrm{~min}$ at room temperature and observed under a confocal microscope (Zeiss). Three populations of cells were predominantly visible: viable cells were both Annexin-V and PI negative, cells undergoing apoptosis were Annexin$V$ single positive, and late-stage apoptosis or necrotic cells were either Annexin-V and PI positive or PI single positive.

RNA isolation

Total RNA was extracted using TRIzol reagent (Invitrogen, San Diego, CA, USA), following the manufacturer's instructions. Quantification of RNA yield and purity were assessed using a NanoDrop ND-1000 (Thermo Fisher Scientific Inc., USA). The RNA integrity number (RIN) value was ascertained using an Agilent RNA6000 Nano assay (Agilent technologies, Germany) and used as a measure of RNA integrity.

\section{Gene expression microarray and qRT-PCR}

For hybridization, $10 \mu \mathrm{g}$ of Cy5-labeled aRNA was utilized in the Phalanx Hybridization Protocol Array Version HOA6.1. qRT-PCR was also employed to corroborate putative results. QRT-PCR was carried out in $20 \mu \mathrm{l}$ reaction volumes using SYBR Green PCR mix (Roche) and run on an Applied Biosystem's 7500 instrument, Singapore. The relative differences ( $n$-fold) in gene expression were normalized to the level of the housekeeping gene $\beta$-actin as well as designated controls as a reference. Primer sequences were obtained from the Primer Bank database (http://pga.mgh.harvard. edu/primerbank/) and Primer Premier 5 (Table 2).

Immunobloting analysis

Protein extraction was performed using cell lysis buffer and $1 \mathrm{mM}$ phenylmethanesulfonyl-fluoride (Beyotime). The supernatant was collected and quantified using a BCA reagent (Beyotime) and according to the manufacturer's instructions. Equal amounts of protein were separated using $10 \%$ SDS-PAGE. Proteins were subsequently transferred to PVDF membranes and blocked in $5 \%$ bovine serum albumin at room temperature for $1 \mathrm{~h}$. Targeted proteins were probed with the following primary antibodies: rabbit monoclonal antibody to phospho-AKT $(1: 2000)$, AKT $(1: 1000)$, and phospho-p53 $(1: 1000)$. All antibodies were obtained from Cell Signaling Technology (Frankfurt, Germany). Membranes were incubated with a given primary antibody overnight at $4{ }^{\circ} \mathrm{C}$, then with appropriate HRP-conjugated secondary antibody for $1 \mathrm{~h}$ at room temperature. Resulting immunocomplexes were visualized using a chemiluminescent autography detection system (Beyotime). Protein levels were normalized by probing the membranes for $\beta$-actin $(1: 1000$; KangChen, Shanhai, China).

Construction of pLL3.7/shRNA plasmid and lentivirus packaging Three pairs of shRNA oligonucleotides against human GADD45a were designed. An Hpal site was introduced into the $5^{\prime}$ end and an Xhol site was introduced into the $3^{\prime}$ end of the shRNA sequence. The shRNA sequences used to target GADD45a were as follow: 5'-TAACGTCGACCCCGATAACGTG- 
TTCAAGAGACACGTTATCGGGGTCGACGTIITITC-3'; 5'-TAACATCCTGCGCG TCAGCAACTTCAAGAGAGTTGCTGACGCGCAGGATGTIIIIITC-3'; 5'-TAAAG TCGCTACATGGATCAATTTCAAGAGAATTGATCCATGTAGCGACTIIITITITC-3'. BLAST searches were performed using the National Center for Biotechnology Information (NCBI) database to ensure that the shRNA constructs were targeting only human GADD45a. Oligos were annealed and cloned into the Xhol site of the pLL3.7 vector. HEK293/17 cells were planted on $10 \mathrm{~cm}$ dishes in DMEM containing $10 \%$ fetal bovine serum and transfected with $4 \mu \mathrm{g}$ of pLL3.7/shRNA or pLL3.7, $4 \mu \mathrm{g}$ of the packaging plasmid pSpAX2, and $2 \mu \mathrm{g}$ of the envelope plasmid pMD2.G using the calcium-phosphate method. Infectious lentiviruses were harvested at $48 \mathrm{~h}$ post transfection, filtered through $0.2 \mu \mathrm{m}$ syringe filters, and used to transfect ARPE-19 cells and primary human fibroblast controls.

\section{GADD45a overexpression}

The gene encoding GADD45a was amplified by PCR from CDNA obtained from ARPE-19 cells using the following forward primer containing an HindIII site: 5'-GCAAGCTTATGACTITGGAGGAATTCTCGGCTGG-3' and the following reverse primer containing a Xhol site: $5^{\prime}$-CCTCGAGTCACCG TTCAGGGAGATTAATCACTG-3'. The final PCR product was cloned into the corresponding sites within the pCMV-tag $2 \mathrm{~b}$ vector. The recombinant plasmid was transfected into the ARPE-19 cells and control (primary human fibroblasts) using Lipofectamine 2000 (Invitrogen) and according to the manufacturer's protocols.

\section{Ly294002 treatment}

ARPE-19 cells pretreated with $20 \mu \mathrm{M}$ Ly294002 (Selleckchem, Burlington, NC, USA) for $6 \mathrm{~h}$ before light exposure.

\section{Statistical analysis}

Unpaired $t$-tests and analysis of variance were used to determine differences using Graphpad Prism (California Corporation, San Diego, CA, USA). Error bars in all graphical figures represent the standard error of the mean (S.E.M.). Differences were considered to be statistically significant at $P<0.05$.

\section{ABBREVIATIONS}

GADD45a, growth arrest and DNA damage-45 alpha; RPE, retinal pigmented epithelium; LEDs, light-emitting diodes; PI3K, phosphatidylinositol 3-kinase; Pl, propidium iodide; GO, Gene ontology; qRT-PCR, quantitative reverse transcription-PCR; shRNA, short hairpin RNA; DMEM, Dulbecco's modified Eagle's medium; FBS, fetal bovine serum.

\section{ACKNOWLEDGEMENTS}

We thank Dr. Dong-Qing Li and all lab members for the technical supports and critical discussion. This study was supported by Zhejiang Provincial Natural Science Foundation of China (LR13H120001, Q14B020018), NHFPC Grant-in-Aid for Medical and Health Science (201472911), the National Basic Research Program of China (2013CB967502) and National Natural Science Foundation of China (81522014, 81371059, 8150030673), MOST major projects (2012YQ12008004) and partly funded by Public Project of Zhejiang Province (2013C33170), the Wenzhou Science and Technology Innovation Team Project (C20150004), Zhejiang Technology Development Program (2013C33170).

\section{COMPETING INTERESTS}

The authors declare no conflict of interest.

\section{REFERENCES}

1 Hadziahmetovic M, Kumar U, Song Y, Grieco S, Song DL, Li YF et al. Microarray analysis of murine retinal light damage reveals changes in iron regulatory, complement, and antioxidant genes in the neurosensory retina and isolated RPE. Invest Ophthalmol Vis Sci 2012; 53: 5231-5241.

2 Hunter JJ, Morgan JIW, Merigan WH, Sliney DH, Sparrow JR, Williams DR. The susceptibility of the retina to photochemical damage from visible light. Prog Retin Eye Res 2012; 31: 28-42.

$3 \mathrm{Xu} \mathrm{JY,} \mathrm{Wu} \mathrm{LY,} \mathrm{Zheng} \mathrm{XQ,} \mathrm{Lu} \mathrm{JL,} \mathrm{Wu} \mathrm{MY,} \mathrm{Liang} \mathrm{YR.} \mathrm{Green} \mathrm{tea} \mathrm{polyphenols}$ attenuating ultraviolet $b$-induced damage to human retinal pigment epithelial cells in vitro. Invest Ophthalmol Vis Sci 2010; 51: 6665-6670.
4 Sui GY, Liu GC, Liu GY, Gao YY, Deng Y, Wang WY et al. Is sunlight exposure a risk factor for age-related macular degeneration? A systematic review and meta-analysis. Br J Ophthalmol 2013; 97: 389-394.

5 Busch EM, Gorgels T, van Norren D. Temporal sequence of changes in rat retina after UV-A and blue light exposure. Vision Res 1999; 39: 1233-1247.

6 Gorgels T, Vannorren D. Ultraviolet and green light cause different types of damge in rat retina. Invest Ophthalmol Vis Sci 1995; 36: 851-863.

7 Walsh CM, Prendergast RL, Sheridan JT, Murphy BA. Blue light from light-emitting diodes directed at a single eye elicits a dose-dependent suppression of melatonin in horses. Vet J 2013; 196: 231-235.

8 West KE, Jablonski MR, Warfield B, Cecil KS, James M, Ayers MA et al. Blue light from light-emitting diodes elicits a dose-dependent suppression of melatonin in humans. J Appl Physiol 2011; 110: 619-626.

9 Hao WS, Wenzel A, Obin MS, Chen CK, Brill E, Krasnoperova NV et al. Evidence for two apoptotic pathways in light-induced retinal degeneration. Nature Genet 2002; 32: $254-260$.

10 Schmitz-Valckenberg S, Guo L, Cheung W, Moss SE, Fitzke FW, Cordeiro MF. In vivo imaging of retinal cell apoptosis following acute light exposure. Ophthalmologe 2010; 107: 22-29.

11 Wielgus AR, Collier RJ, Martin E, Lih FB, Tomer KB, Chignell CF et al. Blue light induced $A 2 E$ oxidation in rat eyes - experimental animal model of dry AMD. Photochem Photobiol Sci 2010; 9: 1505-1512.

12 Sparrow JR, Cai BL. Blue light-induced apoptosis of A2E-containing RPE: Involvement of caspase-3 and protection by bcl-2. Invest Ophthalmol Vis Sci 2001; 42: 1356-1362.

13 Sparrow JR, Parish C, Nakanishi K. The lipofuscin fluorophore, A2E, mediates blue light-induced damage to retinal pigment epithelial (RPE) cells in culture. Invest Ophthalmol Vis Sci 2000; 41: S145-S145.

14 Godley BF, Shamsi FA, Liang FQ, Jarrett SG, Davies S, Boulton M. Blue light induces mitochondrial DNA damage and free radical production in epithelial cells. $J$ Biol Chem 2005; 280: 21061-21066.

15 Chahory S, Keller N, Martin E, Omri B, Crisanti P, Torriglia A. Light induced retinal degeneration activates a caspase-independent pathway involving cathepsin $D$. Neurochem Int 2010; 57: 278-287.

16 King A, Gottlieb E, Brooks DG, Murphy MP, Dunaief JL. Mitochondria-derived reactive oxygen species mediate if blue light-induced death of retinal pigment epithelial cells. Photochem Photobiol 2004; 79: 470-475.

17 Shang YM, Wang GS, Sliney D, Yang CH, Lee LL. White Light-Emitting Diodes (LEDs) at Domestic Lighting Levels and Retinal Injury in a Rat Model. Environ Health Perspect 2014; 122: 269-276.

18 Behar-Cohen F, Martinsons C, Vienot F, Zissis G, Barlier-Salsi A, Cesarini JP et al. Light-emitting diodes (LED) for domestic lighting: Any risks for the eye? Prog Retin Eye Res 2011; 30: 239-257.

19 Andersen JL, Zimmerman ES, DeHart JL, Murala S, Ardon O, Blackett J et al. ATR and GADD45 alpha mediate HIV-1 Vpr-induced apoptosis. Cell Death Differ 2005; 12: $326-334$

20 Hollander MC, Fornace AJ. Genomic instability, centrosome amplification, cell cycle checkpoints and Gadd45a. Oncogene 2002; 21: 6228-6233.

21 Mandal MNA, Patlolla JMR, Zheng L, Agbaga MP, Tran JTA, Wicker L et al. Curcumin protects retinal cells from light-and oxidant stress-induced cell death. Free Radic Biol Med 2009; 46: 672-679.

22 Knels L, Valtink M, Roehlecke C, Lupp A, de la Vega J, Mehner M et al. Blue light stress in retinal neuronal (R28) cells is dependent on wavelength range and irradiance. Eur J Neurosci 2011; 34: 548-558.

23 Arnault E, Barrau C, Nanteau C, Gondouin P, Bigot K, Vienot F et al. Phototoxic action spectrum on a retinal pigment epithelium model of age-related macular degeneration exposed to sunlight normalized conditions. PLoS One 2013; 8: e71398.

24 Fris M, Tessem MB, Cejkova J, Midelfart A. The effect of single and repeated UVB radiation on rabbit cornea. Graefes Arch Clin Exp Ophthalmol 2006; 244: 1680-1687.

25 Lin DPC, Chang HH, Yang LC, Huang TP, Liu HJ, Chang LS et al. Assessment of ultraviolet B-blocking effects of weekly disposable contact lenses on corneal surface in a mouse model. Mol Vision 2013; 19: 1158-1167.

26 Tessem MB, Midelfart A, Cejkova J, Bathen TF. Effect of UVA and UVB irradiation on the metabolic profile of rabbit cornea and lens analysed by HR-MAS H-1 NMR spectroscopy. Ophthalmic Res 2006; 38: 105-114.

27 Resnikoff S, Pascolini D, Etya'ale D, Kocur I, Pararajasegaram R, Pokharel GP et al. Global data on visual impairment in the year 2002. Bull World Health Organ 2004; 82: 844-851.

$28 \mathrm{Wu}$ JM, Seregard S, Algvere PV. Photochemical damage of the retina. Survey Ophthalmol 2006; 51: 461-481.

29 Rózanowska M, Jarvis-Evans J, Korytowski W, Boulton ME, Burke JM, Sarna T. Blue light-induced reactivity of retinal age pigment in vitro generation of oxygen-reactive species. J Biol Chem 1995; 270: 18825-18830. 
30 Zhan QM, Antinore MJ, Wang XW, Carrier F, Smith ML, Harris CC et al. Association with Cdc2 and inhibition of Cdc2/cyclin B1 kinase activity by the p53-regulated protein Gadd45. Oncogene 1999; 18: 2892-2900.

31 Smith ML, Chen IT, Zhan QM, Bae IS, Chen CY, Gilmer TM et al. Interaction of the P53-regulated protein GADD45 with proliferating cell nuclear antigen. Science 1994; 266: 1376-1380.

32 El-Deiry WS. Regulation of p53 downstream genes. Sem Cancer Biol 1998; 8: 345-357.

33 Zhan QM, Carrier F, Fornace AJ. Indection of cellular P53 activity by DNAdamaging agents and growth arrest. Mol Cell Biol 1993; 13: 4242-4250.

34 Mo MS, Li HB, Wang BY, Wang SL, Zhu ZL, Yu XR. PI3K/AKT and NF-kappa B activation following intravitreal administration of 17 beta-estradiol: Neuroprotection of the rat retina from light-induced apoptosis. Neuroscience 2013; 228: $1-12$.

35 Bito T, Sumita N, Masaki T, Shirakawa T, Ueda M, Yoshiki R et al. Ultraviolet light induces Stat3 activation in human keratinocytes and fibroblasts through reactive oxygen species and DNA damage. Exp Dermatol 2010; 19: 654-660.

36 Mahajan K, Mahajan NP, PI3K-independent AKT. activation in cancers: A treasure trove for novel therapeutics. J Cell Physiol 2012; 227: 3178-3184.

37 Chimge NO, Makeyev AV, Waigel SJ, Enkhmandakh B, Bayarsaihan D. PI3K/ Akt-dependent functions of TFII-I transcription factors in mouse embryonic stem cells. J Cell Biochem 2012; 113: 1122-1131.

38 Graupera M, Potente M. Regulation of angiogenesis by PI3K signaling networks. Exp Cell Res 2013; 319: 1348-1355.

39 Feldman ME, Apsel B, Uotila A, Loewith R, Knight ZA, Ruggero D et al. Active-site inhibitors of mTOR target rapamycin-resistant outputs of mTORC1 and mTORC2. PLOS Biol 2009; 7: 371-383.
40 Cheng D, Zhao L, Zhang LL, Jiang YF, Tian Y, Xiao XQ et al. p53 controls hepatitis C virus non-structural protein 5A-mediated downregulation of GADD45 alpha expression via the NF-kappa B and PI3K-Akt pathways. J Gen Virol 2013; 94: 326-335.

41 Dunn KC, AotakiKeen AE, Putkey FR, Hjelmeland LM. ARPE-19, a human retinal pigment epithelial cell line with differentiated properties. Exp Eye Res 1996; 62: 155-169.

42 Ahmado A, Carr AJ, Vugler AA, Semo M, Gias C, Lawrence JM et al. Induction of differentiation by pyruvate and DMEM in the human retinal pigment epithelium cell line ARPE-19. Invest Ophthalmol Vis Sci 2011; 52: 7148-7159.

43 Rodemann HP, Bayreuther K. Abnormal collagen-metabolism in cultured skin fibroblasts from patient with duchenne muscular-dystrophy. Proc Natl Acad Sci USA 1984; 81: 5130-5134.

44 Oram JF, Brinton EA, Bierman EL. Regulation of high-density lipoprotein receptor activity in cultured human-skin fibroblasts and human arterial smoothmuscle cells. J Clin Invest 1983; 72: 1611-1621.

45 Sandu C, Dumas M, Malan A, Sambakhe D, Marteau C, Nizard C et al. Human skin keratinocytes, melanocytes, and fibroblasts contain distinct circadian clock machineries. Cell Mol Life Sci 2012; 69: 3329-3339.

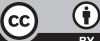

This work is licensed under a Creative Commons Attribution 4.0 International License. The images or other third party material in this article are included in the article's Creative Commons license, unless indicated otherwise in the credit line; if the material is not included under the Creative Commons license, users will need to obtain permission from the license holder to reproduce the material. To view a copy of this license, visit http://creativecommons.org/licenses/ by/4.0/

Supplementary Information accompanies the paper on the Cell Death and Discovery website (http://www.nature.com/cddiscovery) 